\title{
Effect of coenzyme Q10 on organ damage in sepsis
}

\author{
Abitagaoglu S ${ }^{1}$, Akinci SB${ }^{1}$, Saricaoglu $\mathrm{F}^{1}$, Akinci $\mathrm{M}^{2}$, Zeybek ND ${ }^{3}$, Muftuoglu $\mathrm{S}^{3}$, Aypar $\mathrm{U}^{1}$ \\ Department of Anaesthesiology and Reanimation, Hacettepe University Faculty of Medicine, Sihhiye, \\ Ankara, Turkey. suheylaatay81@gmail.com
}

\section{ABSTRACT}

OBJECTIVE: Investigating the effects of coenzyme Q10 on organ damage and survival on mice in cecal ligation perforation (CLP) model in sepsis.

BACKGROUND: Coenzyme Q10 is an antioxidant molecule playing an important role in mitochondria. Mitochondrial dysfunction is an important mechanism in sepsis pathophysiology.

METHODS: Nintyfour Swiss Albino male mice were divided into 8 groups. CLP was performed in Group I. Coenzyme Q10, $100 \mathrm{mg} / \mathrm{kg}$ subcutaneously, was given 5 hours after CLP to Group II and 20 hours after CLP to Group III. Sham operation was performed in Group IV, $100 \mathrm{mg} / \mathrm{kg}$ coenzyme Q10 subcutaneously was given 5 hours after sham operation to Group $\mathrm{V}$ and 20 hours after sham operation to Group VI. No operation was performed in Group VII; coenzyme Q10, $100 \mathrm{mg} / \mathrm{kg}$ subcutaneously, was given to Group VIII. Antibiotics and fluid replacement were applied for 3 days. The mice still living were sacrificed at 576 th hour. The organ damages were scored under light microscopy.

RESULTS: The survival of Group I and Group II was lower than that of the control groups, but the survival in the Group III was similar to control groups. It was established that spleen, kidney, heart damage and total organ damage were decreased when compared to CLP group.

CONCLUSIONS: Coenzyme Q10 is effective in decreasing histological organ damage in sepsis (Tab. 3. Fig. 1, Ref. 30). Text in PDF www.elis.sk.

KEY WORDS: coenzyme Q10, sepsis, intestinal perforation, mitochondria, antioxidants, death rate.

\section{Introduction}

Sepsis, a systemic inflammatory response to infection, is an important cause of death in intensive care units. Only in United States approximately 215000 patients die from sepsis each year (1). It is known that energy-metabolism disturbances during sepsis are characterized by enhanced glycolytic fluxes and reduced mitochondrial respiration (2). High mortality (60-80\%) in sepsis is caused by proinflammatory cytokines and various early and late mediators.

A mitochondrial network in neutrophils was recently described besides the primary role of neutrophils in pathophysiology of acute sepsis. Mitochondria play an essential role in cellular viability and

${ }^{1}$ Department of Anaesthesiology and Reanimation, Hacettepe University Faculty of Medicine, Sihhiye, Ankara, Turkey, ${ }^{2}$ Department of General Surgery, Diskapi Public Hospital, Ankara, Turkey, and ${ }^{3}$ Department of Histology and Embryology, Hacettepe University Faculty of Medicine, Sihhiye, Ankara, Turkey

Address for correspondence: Hacettepe University Faculty of Medicine Department of Anesthesiology and Reanimation, 06100 Sihhiye, Ankara, Turkey.

Phone: +90.532 .5267656$

Acknowledgements: All authors that have contributed to the paper, met the criteria of authorship and are familiar with the contents of the final draft. There is no conflict of interest with any financial organization. The authors have not received funding for research of the article. Experimental Animals Ethics Committee of Hacettepe University Medical Faculty approved (2010/17-2) the procedures. metabolism. Mitochondria have important roles in intracellular energy generation, modulation of apoptosis, and redox-dependent intracellular signaling. Initial studies indicated that modulation of mitochondrial membrane potentially influences neutrophil chemotaxis (3). In addition, mitochondria produce large amounts of reactive oxygen species (ROS) which is involved in eradication of bacteria and other pathogens. However, excessive production of ROS by neutrophils can be deleterious, contributing to organ system dysfunction in inflammatory conditions, such as sepsis or acute lung injury (4). Recently in a review study the importance of mitochondria-targeted antioxidants in sepsis was emphasized (5).

Mitochondrial dysfunction has been identified in various animal models. Hypertrophic mitochondria have been encountered in the livers of patients dying from severe sepsis, which have been attributed to a decrease in Complex I-IV activity.

In this study, a hypothesis was put forward proposing that mitochondrial enzymes might constitute a potential treatment option in sepsis, if oxidative stress directed to the mitochondria plays a central role in the pathophysiology of sepsis. For this reason, it was thought that the coenzyme Q10 might be a treatment option. Coenzyme Q10, a mitochondrial coenzyme, has an antioxidative effect due to its electron transfer ability. It has gained popularity nowadays due to its antioxidative and anti-inflammatory roles especially in cardiac diseases and hypertension. The levels of important proinflammatory cytokines such as IL-6 and TNF-alpha play significant role in the development of congestive heart failure, acute myocardial infarction and hypertension. In many stud- 
433-439

ies, these cytokines have been shown to decrease noticeably as a result of oral coenzyme Q10 intake (6).

It is known that many inflammatory mediators are released during the development of sepsis (7). The most frequently encountered metabolic state in sepsis is the increase in lactate levels. A possible cause for this might be activation of glycolysis, in association with mitochondrial dysfunction due to decreased coenzyme Q10 levels (2).

Cecal ligation and perforation (CLP) is a preferred method to demonstrate systemic response to local infection. Peritonitis originating from the mixed intestinal flora is performed by perforation. In this model, the hyperdynamic and hypodynamic phases of sepsis are encountered at the 5th and 20th hour after ligation, respectively (8).

This study aimed to evaluate the effects of coenzyme Q10 administration at the 5th and 20th hour on organ damage and survival in mice on sepsis induced by cecal ligation and perforation.

\section{Materials and methods}

Experimental Animals Ethics Committee of the Hacettepe University Medical Faculty approved (2010/17-2) the procedures. Male Swiss albino mice (weighing between 20-40 g) were supplied from Animal Husbandry Facility of Hacettepe University. Mice were monitored at $22 \pm 3{ }^{\circ} \mathrm{C}$ and $30 \%$ to $70 \%$ relative humidity and with 12 hours dark / 12 hours bright cycles (with the time period from 7 am to $7 \mathrm{pm}$ being bright). Mice were provided with tap water and standard laboratory animal feed (KorkutelimYem; Sanayi, Antalya, Turkey)

\section{Experimental groups}

Ninety-four Swiss Albino male mice were randomly divided into 8 groups.

Group 1: CLP $(\mathrm{n}=14)$

Group II: CLP - Coenzyme Q10 administeredd at 5th hour $(\mathrm{n}=14)$

Group III: CLP - Coenzyme Q10 administered at 20th hour $(\mathrm{n}=14)$

Group IV: Sham $(\mathrm{n}=12)$

Group V: Sham - Coenzyme Q10 administered at 5th hour $(\mathrm{n}=12)$ Group VI: Sham - Coenzyme Q10 administered at 20th hour (n $=12$ )

Group VII: Control $(\mathrm{n}=8)$

Group VIII: Control - Coenzyme Q10 present $(n=8)$

After all of the mice were anesthetized with subcutaneous ketamine hydrochloride (Ketalar Flacon, Pfizer, Istanbul) $(80 \mathrm{mg}$ / $\mathrm{kg}$ ) and subcutaneous xylazine (Alfazyne 2\% Injectable, Alfasan International B.V. Holland) $(16 \mathrm{mg} / \mathrm{kg})$, peritonitis was introduced by the same general surgeon, with cecal ligation and perforation being applied.

Anesthetized mice were fixed in supine position and their anterior abdominal wall was disinfected with ethanol. Peritoneum was entered through a $1 \mathrm{~cm}$ incision of the left lower quadrant. The cecum was located and its $1 / 3$ distal section was tied with a 3-0 silk suture. The cecum was perforated at two points with the aid of a needle $(20 \mathrm{G})$. A little amount of feces was removed from the cecum by slightly squeezing it. Cecum was introduced back into its original position in the peritoneum and the abdomen was closed with a 4-0 absorbable suture.

Cecum was introduced back into the abdomen without ligation and perforation in the sham control group. Three hours after the procedure, Ceftriaxone (Iesef injectable vial, I.E. Ulugay) at a dose of $30 \mathrm{mg} / \mathrm{kg}$ and clindamycin (Cleocin ampul, Eczacibaşi) at a dose of $30 \mathrm{mg} / \mathrm{kg}$ were administered intramuscularly every 8 hours for the following three days to all of the groups. Subcutaneous coenzyme Q10 (Coenzyme Q10, Sigma-Aldrich) was administered at a dose of $100 \mathrm{mg} / \mathrm{kg}$ at the $5^{\text {th }}$ postoperative hour to 3 of the groups; one of each CLP, Sham and Control groups, and also at the 20th hour to 2 of the groups; one of each, CLP and Sham groups.

For all of the groups, $0.045 \mathrm{NaCl}$ solution was administered subcutaneously for fluid replacement following ligation; it was administered at the 6th and 12th hour at a dose of $100 \mathrm{ml} / \mathrm{kg}$ and at a dose of $35 \mathrm{ml} / \mathrm{kg}$ every 6 hours after 18 th hour for 3 days. In addition, tramadol (Contramal ampul, Abdi Ibrahim) $1 \mathrm{~mL}$ (20 $\mathrm{mcg} / \mathrm{g}$ ) was administered to all animals subcutaneously as an analgesic after cecal ligation and perforation procedure.

The mice were observed until they awake and were enumerated, and then taken to the location where they would be monitored. Their hourly mortality was followed. The death hours were recorded in all groups. Animals which were alive on the 24th day after cecal ligation and perforation were sacrificed with high dose of ketamine. The lung, heart, liver, kidney and spleen of the mice were isolated and fixed in $10 \%$ formaldehyde.

\section{Histopathological evaluation}

Formalin-fixed tissues were dehydrated through a graded ethanol series, cleared in xylene and embedded in paraffin blocks by standard procedures. Five micrometer thick sections were stained with hematoxylin-eosin and Masson's trichrome according to standard protocols. The sections were examined and photographed by using a light microscope (Leica DM6000B, Wetzlar, Germany) with a DC490 digital camera (Leica, Wetzlar, Germany).

Two histologists, who were blinded to the experimental groups, examined the stained sections. The specimens were graded on a four-point scale ranging from 0 to 3 depending on whether the finding was absent: 0 , mild: 1 , moderate: 2 , or severe: 3 (9). The lung specimens were evaluated for the presence of pulmonary edema, congestion in the parenchyma, alveolar hemorrhage, peribronchial inflammation, perivascular inflammation, and interstitial inflammation. The lung injury score was calculated by summing the scores of these six parameters (maximum score 18). The liver specimens were evaluated for the presence of ischemic necrosis, congestion in the parenchyma, hepatocellular injury, periportal inflammation, and vacuolar degeneration. The liver injury score was calculated by summing the scores of these five parameters (maximum score 15). Congestion, fibrosis and presence of giant cell were evaluated for spleen injury (maximum score 9). Kidney specimens were evaluated according to the presence of congestion and necrosis. Kidney injury score was calculated by adding the scores of these two parameters. The heart specimens were evaluated for the pres- 
ence of congestion in the parenchyma, necrosis and infiltration in the parenchyma. Total organ injury score was calculated by adding these parameters (maximum score 54).

\section{Statistical analysis}

Statistical analysis was performed with the SPSS 16.0 program. The level of significance was accepted as $p<0.05$ in collective comparisons performed in the eight groups. Kolmogorov-Smirnov test was used to assess the distribution of the data. Numerical variables with normal distribution were given as mean $\pm \mathrm{SD}$. Groups were analyzed with ANOVA, while the t-test and Bonferroni corrections were used in post hoc comparisons. Data without normal distribution were expressed as median values (minimummaximum). The Kruskal-Wallis test was used for comparisons of nonparametric histopathological organ damage scores between all groups, while the Mann-Whitney $U$ test was used for paired comparisons. In paired comparisons, $\mathrm{p}<0.0017$ was accepted as significant.

\section{Results}

Nine of 14 mice in CLP group died before 576th hour and the survival rate was $35.7 \%$. The survival rate of this group was lower than control and control+ Q10 groups $(p<0.0017)$. There was no significant difference when compared to other groups (Tab. 1). In $\mathrm{CLP}+5$ th hour Q10 group 10 mice died and the survival rate was $28.5 \%$; this rate was lower than Control and Control+Q10 groups $(\mathrm{p}<0.0017)$ (Tab. 1). In CLP+20th hour Q10 group 7 mice died, survival rate of this group was $50 \%$ (Tab. 1). This survival rate was similar to all groups $(\mathrm{p}>0.0017)$.

Histopathological scores of organ injury are summarized in Table 2 and these histopathological changes in each group are shown in Figure 1. An overall histopathological grade assigned to each sample was given in Table 3 . The total organ injury was significantly increased in CLP group compared to control, control+Q10, sham, sham + Q10 groups and CLP+20th Q10 group. The administration of Q10 to CLP group decreased the total organ injury scores. Decrease in the total organ injury score was statistically significant in CLP+20th hour Q10 when compared to CLP.

\section{Discussion}

The current study which evaluated the effects of coenzyme Q10 on organ damage and survival in mice with sepsis induced through a cecal ligation and perforation model, it was observed that cecal ligation and perforation increased total lung, total liver, total spleen, total kidney and total heart damages compared to the sham and control groups. In previous studies, various histo- pathological findings caused by sepsis had been demonstrated in the organs $(10,11,12)$. Interstitial and perivascular inflammation in the lungs, vacuolar degeneration and damage in the liver, and increased organ damage in the spleen and kidney were reported in a study performed on mice with induced sepsis (9). Histological results similar to previous studies have been demonstrated in our study by the CLP model. These findings suggest that the CLP model was effective in our study.

Oxidative damage is one of the factors contributing to cellular damage, organ dysfunction and death (13). Oxidative damage in mitochondria plays an important role in the pathophysiology of sepsis. Mitochondrial complexes decrease after the 18th hour following the cecal ligation and perforation method (14). Evidence of mitochondrial damage at light microscopic level depends on intensity and duration of the event. Total organ injury in our study composed of histopathological criteria like edema, congestion, leukocyte infiltration, cellular damage and necrosis are used in order to identify the effects of sepsis on organs at light microscopic level. In our study, for the group that received coenzyme Q10 at the 20th hour after CLP, total organ damage decreased and the survival rate approached the rate observed in the control groups. These findings support the observations concerning the positive effects of coenzyme Q10 in sepsis through mitochondrial enzymes. It is known that coenzyme Q10 exerts a powerful antioxidant property by directly reacting with free radicals in the lysosome, the Golgi apparatus and the plasma membrane, in addition to the mitochondria (15). Although the efficacy of antioxidant support treatment for sepsis has not been sufficiently determined yet, there are many studies in which positive results have been obtained with antioxidant treatment $(16,17,18,19)$.

In a study by Lelli et al performed on dogs it was demonstrated that coenzyme Q10 supported cardiovascular hemodynamics and inhibited lipid peroxidation caused by free radicals during septic shock induced by viable E. coli models (20). In our current study it is believed that coenzyme Q10 administered in septic mice reduced oxidative stress and cytopathic hypoxia in the mitochondria by increasing the activity of the complexes on the mitochondrial membrane, and that coenzyme Q10 also exerted an anti-inflammatory effect by decreasing the production of pro-inflammatory cytokines and free oxygen radicals.

The time period between 2 nd and 10th hour after CLP is defined as the early and hyperdynamic phase of sepsis. Late and hypodynamic phase of sepsis starts after the 16th hour from the CLP. The similarity of the damages observed in organs other than heart damage with the damage observed in the CLP group in animals administered with coenzyme Q10 at the 5th hour following CLP can be attributed to the increased tissue perfusion in the hyperdynamic phase. In a study investigating the changes in the heart and mito-

Tab. 1. Survival rate.

\begin{tabular}{|c|c|c|c|c|c|c|c|c|c|}
\hline & CLP & $\begin{array}{c}\text { CLP+ } \\
\text { 5th hr Q10 }\end{array}$ & $\begin{array}{c}\text { CLP+ } \\
\text { 20th hr Q10 }\end{array}$ & SHAM & $\begin{array}{l}\text { SHAM+ } \\
\text { 5th hr Q10 }\end{array}$ & $\begin{array}{c}\text { SHAM+ } \\
\text { 20th hr Q10 }\end{array}$ & CONTROL & $\begin{array}{c}\text { CONTROL + } \\
\text { Q10 }\end{array}$ & $\mathrm{p}$ \\
\hline Inside group \% & $\Delta \infty 35.7$ & $\Delta \infty 28.5$ & 50 & 92.8 & 92.8 & 85.7 & *\# 100 & $* \# 100$ & $<0.001$ \\
\hline
\end{tabular}


Tab. 2. Organ injury scores.

\begin{tabular}{|c|c|c|c|c|c|c|c|c|c|c|}
\hline & & CLP & $\begin{array}{c}\text { CLP+ } \\
\text { 5th hr Q10 }\end{array}$ & $\begin{array}{c}\text { CLP+ } \\
\text { 20th hr Q10 }\end{array}$ & SHAM & $\begin{array}{c}\text { SHAM+ } \\
\text { 5th hr Q10 }\end{array}$ & $\begin{array}{c}\text { SHAM+ } \\
\text { 20th hr Q10 }\end{array}$ & Control & $\begin{array}{c}\text { Control+ } \\
\text { Q10 }\end{array}$ & $\mathrm{p}$ \\
\hline \multirow{12}{*}{$\begin{array}{l}\text { Pulmonary } \\
\text { Injury } \\
\text { Scores }\end{array}$} & Pulmonary & ${ }^{\mathrm{o} \wedge} \delta \varepsilon \Delta \infty$ & $\Delta$ & $*$ & $*$ & $*$ & $*$ & *\# & $*$ & \\
\hline & Edema & $2.50(1-3)$ & $2(0-2)$ & $1(0-2)$ & $1(0-1)$ & $1(0-1)$ & $1(0-2)$ & $0(0-0)$ & $1(0-1)$ & $<0.001$ \\
\hline & Parenchymal & $\wedge \delta \Delta$ & $\delta$ & & $*$ & *\# & & $*$ & & \\
\hline & Congestion & $2(1-3)$ & $2(1-3)$ & $1(1-3)$ & $1(0-1)$ & $1(0-1)$ & $1(1-2)$ & $1(0-1)$ & $1(0-2)$ & $<0.001$ \\
\hline & Alveolar & $\delta$ & & & & $*$ & & & & \\
\hline & Hemorrhage & $1(1-2)$ & $1(0-1)$ & $0.50(0-1)$ & $0.50(0-1)$ & $0(0-1)$ & $1(0-2)$ & $0(0-1)$ & $1(0-1)$ & 0.002 \\
\hline & Peribronchial & ${ }^{\wedge} \delta \varepsilon \Delta \infty$ & & & $*$ & $*$ & $*$ & $*$ & $*$ & \\
\hline & $\underline{\text { Inflammation }}$ & $2(2-3)$ & $1(1-3)$ & $1.50(1-3)$ & $1(0-1)$ & $1(0-1)$ & $1(0-2)$ & $0(0-1)$ & $1(0-1)$ & $<0.001$ \\
\hline & Perivascular & $\delta \varepsilon \Delta \infty$ & & & & $*$ & $*$ & $*$ & $*$ & \\
\hline & Inflammation & $2(1-3)$ & $1(1-3)$ & $1(1-3)$ & $1(0-1$ & $1(0-1)$ & $1(0-2)$ & $0(0-1)$ & $1(0-1)$ & $<0.001$ \\
\hline & Interstitial & ${ }^{\wedge} \delta \varepsilon \Delta \infty$ & & & $*$ & $*$ & $*$ & $*$ & $*$ & \\
\hline & Inflammation & $2(1-3)$ & $1(1-3)$ & $1(1-3)$ & $1(0-1)$ & $1(0-1)$ & $1(0-2)$ & $0(0-1)$ & $1(0-1)$ & $<0.001$ \\
\hline \multirow{10}{*}{$\begin{array}{l}\text { Liver } \\
\text { Injury } \\
\text { Scores }\end{array}$} & Ischemic & ${ }^{\wedge} \delta \Delta \infty$ & & $\wedge^{\wedge} \Delta$ & $* 0$ & $*$ & & $* 0$ & $* 0$ & \\
\hline & Necrosis & $2(1-3)$ & $1.50(0-3)$ & $1(1-2)$ & $0(0-0)$ & $0(0-2)$ & $1(0-2)$ & $0(0-0)$ & $0(0-0)$ & $<0.001$ \\
\hline & Parenchymal & $\wedge^{\wedge} \delta \Delta \infty$ & $\wedge_{\infty}$ & $\wedge^{\wedge} \Delta \infty$ & $* \#^{0}$ & $*$ & & $* 0$ & $* \#^{\circ}$ & \\
\hline & Congestion & $2(2-3)$ & $2(1-3)$ & $2(1-2)$ & $0(0-1)$ & $1(0-2)$ & $1(0-3)$ & $0(0-1)$ & $0(0-1)$ & $<0.001$ \\
\hline & Hepatocellular & ${ }^{\wedge} \delta \Delta \infty$ & ${ }^{\wedge} \delta \infty$ & $\wedge$ & $* \#^{\mathrm{o}}$ & $* \#^{0}$ & & $*$ & *\# & \\
\hline & Injury & $2(2-3)$ & $2(1-3)$ & $2(1-2)$ & $0.50(0-1)$ & $1(0-2)$ & $2(1-3)$ & $1(0-2)$ & $1(0-1)$ & $<0.001$ \\
\hline & Periportal & ${ }^{\wedge} \delta \infty$ & $\wedge \delta \varepsilon \Delta \infty$ & $\wedge$ & $* \#^{0}$ & $* \#^{0}$ & \# & \# & *\# & \\
\hline & Inflammation & $2(1-3)$ & $2(2-3)$ & $2(1-2)$ & $0(0-0)$ & $0(0-1)$ & $1(0-2)$ & $1(0-2)$ & $1(0-1)$ & $<0.001$ \\
\hline & Vacuolary & ${ }^{\wedge} \delta \Delta$ & ${ }^{\wedge} \delta \Delta$ & $\wedge$ & $* \#^{\circ} \varepsilon$ & $* \#^{\circ} \varepsilon$ & $\wedge^{\wedge} \delta$ & *\# & & \\
\hline & Degeneration & $2(0-3)$ & $1(1-3)$ & $1(1-2)$ & $0(0-0)$ & $0(0-1)$ & $1(1-3)$ & $0(0-1)$ & $0(0-2)$ & $<0.001$ \\
\hline \multirow{6}{*}{$\begin{array}{l}\text { Spleen } \\
\text { Injury } \\
\text { Scores }\end{array}$} & Congestion & ${ }^{\wedge} \delta \Delta$ & ${ }^{\wedge} \delta \varepsilon \Delta$ & $\delta$ & $* \#$ & $* \#^{0}$ & \# & *\# & & \\
\hline & & $2(2-3)$ & $3(2-3)$ & $1.50(0-3)$ & $1(0-1)$ & $0(0-0)$ & $1(0-2)$ & $1(0-2)$ & $1(0-3)$ & $<0.001$ \\
\hline & Fibrosis & ${ }^{\wedge} \delta \varepsilon \Delta \infty$ & & & $*$ & $*$ & $*$ & $*$ & $*$ & \\
\hline & & $1(1-2)$ & $1(0-3)$ & $1(0-1)$ & $0(0-0)$ & $0(0-0)$ & $0(0-1)$ & $0(0-0)$ & $0(0-0)$ & $<0.001$ \\
\hline & Giant Cell & ${ }^{\circ} \delta \varepsilon \Delta$ & & $*$ & & $*$ & $*$ & $*$ & & \\
\hline & & $2(2-3)$ & $2(1-3)$ & $1(1-2)$ & $1(1-2)$ & $1(0-1)$ & $1(0-1)$ & $1(0-1)$ & $1(1-2)$ & $<0.001$ \\
\hline \multirow{4}{*}{$\begin{array}{l}\text { Renal } \\
\text { Injury } \\
\text { Scores }\end{array}$} & Congestion & ${ }^{\circ \wedge} \delta \Delta \infty$ & $\wedge^{\wedge} \delta \Delta \infty$ & $*$ & $* \#$ & $* \#$ & & $* \#$ & *\# & \\
\hline & & $2(2-3)$ & $2(1-3)$ & $1(1-2)$ & $0.50(0-1)$ & $1(0-1)$ & $1.50(1-2)$ & $0(0-1)$ & $0(0-1)$ & $<0.001$ \\
\hline & Necrosis & ${ }^{\circ \wedge} \delta \varepsilon \Delta \infty$ & $\delta \Delta \infty$ & $*$ & $*$ & $* \#$ & $*$ & $* \#$ & *\# & \\
\hline & & $2(1-3)$ & $2(0-3)$ & $1(0-2)$ & $0(0-1)$ & $0(0-1)$ & $1(0-1)$ & $0(0-0)$ & $0(0-0)$ & $<0.001$ \\
\hline \multirow{5}{*}{$\begin{array}{l}\text { Cardiac } \\
\text { Injury } \\
\text { Scores }\end{array}$} & $\begin{array}{l}\text { Parenchymal } \\
\text { congestion }\end{array}$ & $\begin{array}{c}\delta \Delta \\
1(1-2)\end{array}$ & $1(0-2$ & $0\left(0_{-}\right.$ & $1\left(0_{-}\right.$ & $\begin{array}{c}* \\
0(0-0)\end{array}$ & & $\begin{array}{c}* \\
0(0-0)\end{array}$ & & \\
\hline & Necrosis & $\frac{1}{\#}$ & $*$ & & & $0(0-0)$ & & $0(0-0)$ & & -0.001 \\
\hline & Necrosis & $\begin{array}{c}\# \\
1(0-3)\end{array}$ & $0(0-0)$ & $0(0-1)$ & $0(0-0)$ & $0(0-0)$ & $0(0-1)$ & $0(0-0)$ & $0(0-1)$ & $<0.001$ \\
\hline & Inflammation & ${ }^{\circ \wedge} \delta \varepsilon \Delta \infty$ & ${ }^{\wedge} \delta \Delta$ & $*$ & $* \#$ & $* \#$ & $*$ & $* \#$ & $*$ & \\
\hline & & $2(1-3)$ & $1(1-2)$ & $1(0-1)$ & $0(0-0)$ & $0(0-0)$ & $0(0-1)$ & $0(0-0)$ & $0(0-1)$ & $<0.001$ \\
\hline
\end{tabular}

The specimens from lung. liver, spleen, kidney and heart were graded on a four-point scale ranging from 0 to 3 depending on whether the finding was absent: 0 - mild: $1-$ moderate: 2 - or severe: 3 - Data are presented as Median (minimum-maximum), * When compared to CLP group $\mathrm{p}<0.0017$, \# When compared to CLP +5 th hour group $\mathrm{p}<0.0017,{ }^{\circ}$ When compared to CLP +20 th hour group $\mathrm{p}<0.0017,{ }^{\wedge}$ When compared to Sham group $\mathrm{p}<0.0017, \delta$ When compared to Sham +5 th hour group $\mathrm{p}<0.0017, \varepsilon$ When compared to Sham +20 th hour group $\mathrm{p}<0.0017, \Delta$ When compared to Control group $\mathrm{p}<0.0017, \infty$ When compared to Control+Q10 group $\mathrm{p}<0.0017$

chondrial function of rats in septic shock, it was demonstrated that decreased myocardial contractility was caused by mitochondrial dysfunction and energy deficiency (21). In this study, coenzyme Q10 displayed its effects on the mitochondria-rich heart tissue in the early period. The lower level of total spleen, kidney, heart and total organ damage observed in the CLP + Q10 group at the 20th hour in comparison to the CLP group can be attributed to the hypodynamic phase of sepsis. Thus, it is possible to say that coenzyme Q10 is effective in the late hypodynamic phase of sepsis.

Certain studies define fluid resuscitation as the critical step for the formation of the early, hyperdynamic phase of sepsis (22, $23,24)$. A study had performed a comparison of mortality rates between mice with low (35 ml/kg during CLP), intermediate (35 $\mathrm{ml} / \mathrm{kg}$ during CLP and every 6 hours afterwards), and high (100 $\mathrm{ml} / \mathrm{kg}$ during CLP and $35 \mathrm{ml} / \mathrm{kg}$ every 6 hours afterwards) fluid resuscitation, mortality rates were found to be lower in mice with high fluid resuscitation (25). In another study, the survival rate in mice with no treatment after CLP was $0 \%$, while the survival rate increased to $24 \%$ by fluid resuscitation alone, and to $30 \%$ by antibiotic treatment alone (intramuscular ceftriaxone, $30 \mathrm{mg} / \mathrm{kg}$; and intramuscular application of clindamycin, $30 \mathrm{mg} / \mathrm{kg}$ ). This rate is closer to the survival rate observed in our study.

It has been reported that post-CLP mortality rates can change as a result of the implementation of different antibiotic use and fluid resuscitation protocols (26). In our study, the longer survival periods observed in some of the animals in the CLP group was 


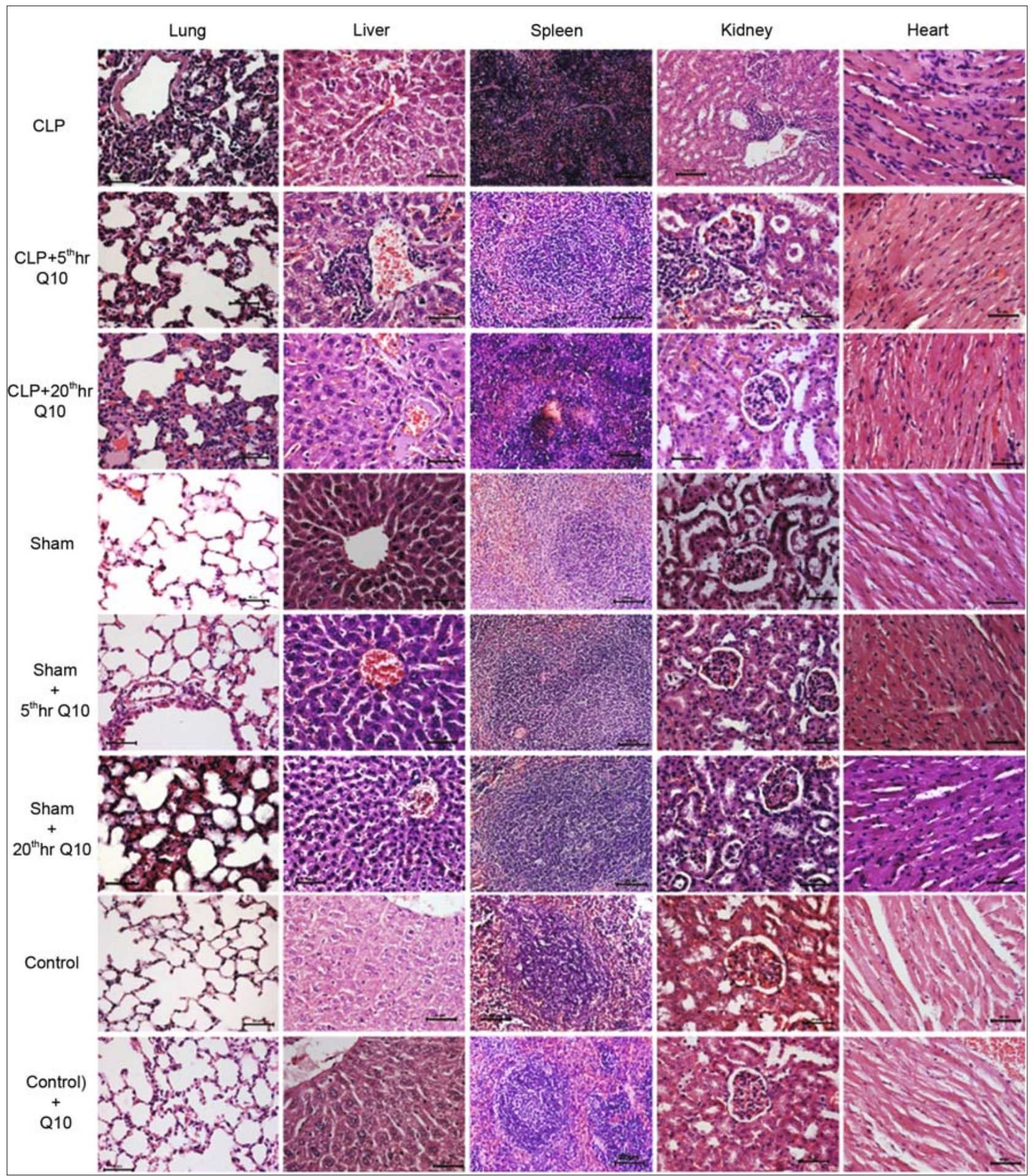

Fig. 1. Light micrographs of lung, liver, spleen, kidney and heart from study groups. (Hematoxyline-Eosin). Lung: In CLP Group diffuse infiltration and congestion; in CLP+5th hour Q10 Group infiltration and congestion; in CLP+20th Q10 Group infiltration; in Sham+20th hour Q10 Group congestion are seen. Liver: In CLP Group neutrophils and vacuolization; in CLP+5th hour Q10 Group neutrophils; in CLP+20th Q10 Group vacuolization; in Sham+20th Q10 Group congestion are seen. Spleen: In CLP Group giant cells; in CLP+5th hour Q10 Group congestion; in CLP+20th Q10 Group infiltration are seen. Kidney: In CLP Group and CLP+5th hour Q10 Group leukocyte infiltration in interstitial space; in CLP+20th Q10 Group and Sham+20th Q10 Group congestion are seen. Heart: In CLP Group significant infiltration and congestion; in CLP+5th hour Q10 Group infiltration are seen. 
Tab. 3. Total organ injury scores.

\begin{tabular}{|c|c|c|c|c|c|c|c|c|c|}
\hline & CLP & $\begin{array}{c}\text { CLP+ } \\
5 \text { th Q10 }\end{array}$ & $\begin{array}{c}\text { CLP+ } \\
\text { 20th hr Q10 }\end{array}$ & SHAM & $\begin{array}{c}\text { SHAM+ } \\
\text { 5th hr Q10 }\end{array}$ & $\begin{array}{c}\text { SHAM+ } \\
\text { 20th hr Q10 }\end{array}$ & Control & $\begin{array}{c}\text { Control+ } \\
\text { Q10 }\end{array}$ & $\mathrm{p}$ \\
\hline \multirow[t]{2}{*}{ Lung } & ${ }^{\wedge} \delta \varepsilon \Delta \infty$ & $\delta \Delta$ & $\Delta$ & $*$ & *\# & $*$ & $* \#^{\circ}$ & * & $<0.001$ \\
\hline & $12 \pm 2.4$ & $8 \pm 2.6$ & $7 \pm 3.1$ & $4 \pm 2.3$ & $3 \pm 2.2$ & $5 \pm 2.4$ & $1 \pm 2.1$ & $5 \pm 1.7$ & \\
\hline \multirow[t]{2}{*}{ Liver } & ${ }^{\wedge} \delta \varepsilon \Delta \infty$ & ${ }^{\wedge} \delta \Delta \infty$ & ${ }^{\wedge} \delta \Delta \infty$ & $*^{*}{ }^{\mathrm{o}} \varepsilon$ & $*^{\circ} \varepsilon$ & ${ }^{* \wedge} \delta \Delta$ & $*^{*} \varepsilon$ & $* \#^{\circ}$ & $<0.001$ \\
\hline & $11 \pm 1.5$ & $9 \pm 2.4$ & $8 \pm 1.8$ & $0 \pm 0.4$ & $2 \pm 2.2$ & $6 \pm 2.9$ & $2 \pm 1.4$ & $2 \pm 0.8$ & \\
\hline Spleen & ${ }^{\mathrm{o} \wedge} \delta \varepsilon \Delta \infty$ & ${ }^{\wedge} \delta \varepsilon \Delta$ & $* \delta$ & $* \#$ & $* \#^{\circ}$ & *\# & $* \#$ & $*$ & $<0.001$ \\
\hline \multirow[t]{2}{*}{ Kidney } & ${ }^{\mathrm{o} \wedge} \delta \varepsilon \Delta \infty$ & ${ }^{\wedge} \delta \Delta \infty$ & $* \Delta$ & $* \#$ & *\# & $* \Delta$ & $*^{*} \varepsilon$ & $* \#$ & $<0.001$ \\
\hline & $4 \pm 0.7$ & $3 \pm 1.2$ & $2 \pm 0.9$ & $0 \pm 0.8$ & $0 \pm 0.6$ & $2 \pm 0.7$ & $0 \pm 0.5$ & $0 \pm 0.5$ & \\
\hline \multirow[t]{2}{*}{ Heart } & $\#^{0 \wedge} \delta \varepsilon \Delta \infty$ & $*$ & $*$ & $*$ & $*$ & $*$ & $*$ & $*$ & $<0.001$ \\
\hline & $4 \pm 1.7$ & $1 \pm 0.9$ & $1 \pm 1.1$ & $0 \pm 0.5$ & $0 \pm 0$ & $1 \pm 1.0$ & $0 \pm 0.0$ & $0 \pm 1.3$ & \\
\hline Total Organ Injury & ${ }^{\mathrm{o} \wedge} \delta \varepsilon \Delta \infty$ & ${ }^{\wedge} \delta \varepsilon \Delta \infty$ & $* \wedge \delta \Delta \infty$ & $* \#^{\mathrm{o}}$ & $* \#^{\mathrm{o}}$ & $* \#$ & $* \#^{\circ}$ & $* \#^{\mathrm{o}}$ & $<0.001$ \\
\hline Score & $38 \pm 5.2$ & $29 \pm 4.8$ & $22 \pm 6.0$ & $9 \pm 2.5$ & $7 \pm 3.5$ & $16 \pm 2.3$ & $5 \pm 3.5$ & $10 \pm 4.1$ & \\
\hline
\end{tabular}

The lung injury score was calculated by adding the scores of pulmonary edema, congestion in the parenchyma, alveolar hemorrhage, peribronchial, perivascular and interstitial inflammation (maximum score 18). The liver injury score was calculated by summing the scores of ischemic necrosis, congestion in the parenchyma, hepatocellular injury, periportal inflammation, and vacuolar degeneration (maximum score 15). The congestion, fibrosis and presence of giant cell were evaluated for spleen injury (maximum score 9). The kidney specimens were evaluated according to the presence of congestion and necrosis (maximum score 6). The heart sp ecimens were evaluated for the $\mathrm{p}$ resence of congestion in the $\mathrm{p}$ arenchyma, necrosis and infiltration in the $\mathrm{p}$ arenchyma (maximum 9 ). Total organ injury score was calculated by adding these $\mathrm{p}$ arameters (maximum score 54). Values are $\mathrm{p}$ resented as Mean $\pm \mathrm{SD}, *$ When comp ared to CLP group $\mathrm{p}<0.0017$, \# When comp ared to CLP +5 th hour group $\mathrm{p}<0.0017,{ }^{\circ} \mathrm{When}$ comp ared to CLP +20 th hour group $\mathrm{p}<0.0017, \wedge$ When comp ared to Sham group $\mathrm{p}<0.0017, \delta$ When comp ared to Sham +5 th hour group $\mathrm{p}<0.0017, \varepsilon \mathrm{When}$ comp ared to Sham +20 th hour group $\mathrm{p}<0.0017, \Delta$ When comp ared to Control group $\mathrm{p}<0.0017, \infty$ When comp ared to Control+Q10 group $\mathrm{p}<0.0017$

considered to be associated with adequate fluid resuscitation and the use of appropriate antibiotic treatments.

There is currently no consensus regarding the dose of coenzyme Q10 that should be used for animal studies. In a study on rats 10 and $100 \mathrm{mg} / \mathrm{kg}$ doses of Coenzyme Q10 were administered (27.). There are certain studies in which coenzyme Q10 is administered to mice at a dose of $10 \mathrm{mg} / \mathrm{kg}$ (28). In the study he conducted with dogs, Lelli administered coenzyme Q10 as a bolus dose of $20 \mathrm{mg} / \mathrm{kg} 10$ minutes prior the commencement of bacterial infusion (17). In a study involving oral coenzyme Q10 administration, Q10 was provided to mice at doses of $200 \mathrm{mg} / \mathrm{kg} /$ day and $400 \mathrm{mg} / \mathrm{kg} /$ day (29). In another study evaluating the antioxidant and healing effects of coenzyme Q10 in mice, the Q10 dose was adjusted as $100 \mathrm{mg} / \mathrm{kg}(30)$.

Certain publications report better clinical results with higher doses of coenzyme Q10 (6). In our study, coenzyme Q10 was administered to the animals at the 5 th and 20th hour as a single, high dose bolus after CLP was induced.

The vacuolar degeneration score for the liver as well as the total liver score were higher in the sham 20th hour coenzyme Q10 group in comparison to the sham group. It is not known how coenzyme Q10 interacts with the liver after surgery. In future studies, it might be necessary to closely monitor liver functions in humans during the post-surgical administration of coenzyme Q10. The absence of differences between the parameters of the Control and the Control+Q10 groups suggests that this effect of Coenzyme Q10 most likely arises in the presence of additional stress factor such as surgery or a SIRS triggering event. The absence of statistically significant differences between the Sham and the Sham + 5th hour Q10 groups, and hence the lack of effects similar to the ones observed when coenzyme Q10 is administered at the 20th hour, suggests that this effect is time-dependent.

Coenzyme Q10 administration to mice with sepsis induced by CLP decreased organ damage and increased survival. But abscess formation and the progression of sepsis in the CLP model may vary in many different ways from the sepsis syndrome observed among humans. Therefore, it would not be possible for the results of the experiments performed on mice to be exactly the same with results that are applicable for different species and humans.

Another drug with antioxidant effects used in our study was ketamine, which was provided for inducing anesthesia. This antioxidant effect of ketamine might have suppressed the effects of CLP on the oxidative pathway. Nevertheless, ketamine was used in all of the groups, and it was hence concluded that ketamine would not engender any differences in the comparisons that were performed.

Because blood drawing changes mortality in mice; further studies are needed to evaluate the relationship between plasma cytokine levels and organ functions.

Survival rate of CLP group is lower compared to controls but there is no significant difference when compared to sham groups; this is probably about the number of mice.

\section{Conclusion}

Coenzyme Q10 administered during the hypodynamic phase of sepsis especially decreases splenic, renal and cardiac damage and organ damage, and also increases the survival rate in mice. However, further experimental studies followed by clinical studies are necessary in order to elucidate coenzyme Q10's effective dose, treatment period, mechanism of action, as well as its role in the pathophysiology of sepsis.

\section{References}

1. Angus DC, Linde-Zwirble WT, Lidicker J, Clermont G, Carcillo J, Pinsky MR. Epidemiology of severe sepsis in the United States: analysis of incidence, outcome, and associated costs of care. Crit Care Med 2001; 29 (7): 1303-1310. 
2. L'Her E, Sebert P. Effects of dichloroacetate and ubiquinone infusions on glycolysis activity and thermal sensitivity during sepsis. J Lab Clin Med 2004; 143 (6): 352-357.

3. Zmijewski JW, Lorne E, Banerjee S, Abraham E. Participation of mitochondrial respiratory complex III in neutrophil activation and lung injury. Am J Physiol Lung Cell Mol Physiol 2009; 296 (4): 624-1634.

4. Zmijewski JW, Lorne E, Zhao X et al. Mitochondrial respiratory complex I regulates neutrophil activation and severity of lung injury. Am J Respir Crit Care Med 2008; 178 (2): 168-179.

5. Rocha M, Herance R, Rovira S, Hernándeze-Mijares A, Victor VM. Mitochondrial dysfunction and antioxidant therapy in sepsis. Infect Disord Drug Targets 2012; 12 (2): 161-178.

6. Kumar A, Kaur H, Devi P, Mohan V. Role of coenzyme Q10 (CoQ10) in cardiac disease, hypertension and Meniere-like syndrome. Pharmacol Therap 2009; 124 (3): 259-268.

7. Comim CM, Rezin GT, Scaini G et al. Mitochondrial respiratory chain and creatine kinase activities in rat brain after sepsis induced by cecal ligation and perforation. Mitochondrion 2008; 8 (4): 313-318.

8. Iskit AB, Senel I, Sokmensuer C, Guc MO. Endothelin receptor antagonist bosentan improves survival in a murine caecal ligation and puncture model of septic shock. Eur J Pharmacol 2004; 506 (1): 83-88.

9. Akinci SB, Ulu N, Yondem OZ et al. Effect of neostigmine on organ injury in murine endotoxemia: missing facts about the cholinergic antiinflammatory pathway. World J Surg 2005; 29 (11): 1483-1489.

10. Koga H, Hagiwara S, Inomata $M$ et al. The New Vitamin E Derivative, ETS-GS, Protects Against Cecal Ligation and Puncture-Induced Systemic Inflammation in Rats. Inflammation, 2011.

11. Lerolle N, Nochy D, Guerot E et al. Histopathology of septic shock induced acute kidney injury: apoptosis and leukocytic infiltration. Intensive Care Med 2010; 36 (3): 471-478.

12. Koskinas J, Gomatos IP, Tiniakos DG et al. Liver histology in ICU patients dying from sepsis: a clinico-pathological study. World J Gastroenterol 2008; 14 (9): 1389-1393.

13. Ritter C, Andrades M, Frota Junior ML et al. Oxidative parameters and mortality in sepsis induced by cecal ligation and perforation. Intensive Care Med 2003; 29 (10): 1782-1789.

14. Levy RJ. Mitochondrial dysfunction, bioenergetic impairment, and metabolic down-regulation in sepsis. Shock 2007; 28 (1): 24-28.

15. Tsunei H. CoenzymeQ10 prevents high glucose-induced oxidative stres in human umbilical vein endothelial cells. Eur J Pharmacol 2007: 314-316

16. Zapelini PH, Rezin GT, Cardoso MR et al. Antioxidant treatment reverses mitochondrial dysfunction in a sepsis animal model. Mitochondrion 2008; 8 (3): 211-218.
17. Lowes DA, Thottakam BM, Webster NR, Murphy MP, Galley HF. The mitochondria-targeted antioxidant MitoQ protects against organ damage in a lipopolysaccharide-peptidoglycan model of sepsis. Free Radic Biol Med 2008; 45 (11): 1559-1565.

18. Atli M, Erikoglu M, Kaynak A, Esen HH, Kurban S. The effects of selenium and vitamin $\mathrm{E}$ on lung tissue in rats with sepsis. Clin Invest Med 2012; 35 (2): E48-54.

19. Zhou G, Kamenos G, Pendem S, Wilson JX, Wu F. Ascorbate protects against vascular leakage in cecal ligation and puncture-induced septic peritonitis. Am J Physiol Regul Integr Comp Physiol 2012; 302 (4): R409-41.6

20. Lelli JL, Drongowski RA, Gastman B, Remick DG, Coran AG. Effects of coenzyme Q10 on the mediator cascade of sepsis. Circ Shock 1993; 39 (3): 178-187.

21. Watts JA, Kline JA, Thornton LR, Grattan RM, Brar SS. Metabolic dysfunction and depletion of mitochondria in hearts of septic rats. J Mol Cell Cardio, 2004; 36 (1): 141-150.

22. Wichterman KA, Baue AE, Chaudry IH. Sepsis and septic shock-a review of laboratory models and a proposal. J Surg Res 1980; 29 (2): 189-201.

23. Rittirsch D, Huber-Lang MS, Flierl MA, Ward PA. Immunodesign of experimental sepsis by cecal ligation and puncture. Nat Protoc 2009; 4 (1): 31-36.

24. Hubbard WJ, Choudhry M, Schwacha MG et al. Cecal ligation and puncture. Shock 2005; 24 (Suppl 1): 52-57.

25. Zanotti-Cavazzoni SL, Guglielmi M, Parrillo JE, Walker T, Dellinger RP, Hollenberg SM. Fluid resuscitation influences cardiovascular performance and mortality in a murine model of sepsis. Intensive Care Med 2009; 35 (4): 748-754.

26. Nemzek JA, Hugunin KM, Opp MR. Modeling sepsis in the laboratory: merging sound science with animal well-being. Comp Med 2008; 58 (2): $120-128$.

27. Sharanova NE, Baturina VA, Vasil'ev AV, Gapparov MM. Effect of coenzyme Q10 on proteomic profile of rat plasma under conditions of metabolic stress. Bull Exp Biol Med 2011; 151 (6): 680-682.

28. Fouad AA, Al-Sultan AI, Refaie SM, Yacoubi MT. Coenzyme Q10 treatment ameliorates acute cisplatin nephrotoxicity in mice. Toxicology 2010; 274 (1-3): 49-56.

29. Saiki R, Lunceford AL, Shi Y et al.Coenzyme Q10 supplementation rescues renal disease in Pdss $2 \mathrm{kd} / \mathrm{kd}$ mice with mutations in prenyl diphosphate synthase subunit 2. Am J Physiol Renal Physiol 2008; 295 (5): F1535-1544.

30. Choi BS, Song HS, Kim HR et al. Effect of coenzyme Q10 on cutaneous healing in skin-incised mice. Arch Pharm Res 2009; 32 (6): 907-913.

Received April 1, 2014. Accepted April 11, 2014. 